\title{
Quantified Land Evaluation (QLE) procedures, a new tool for land-use planning
}

\section{P. M. Driessen}

Centre for World Food Studies, c/o Department of Soil Science and Geology, Agricultural University, P.O. Box 37, 6700 AA Wageningen, Netherlands

\section{Introduction}

Although global food production still increases, per capita production can hardly be maintained at the same level in many developing countries. Two strategies to deal with this problem present themselves: increase food production and implement family planning programmes. Evidently, these two policies are complementary, whereby increasing production is mainly a means to provide short-term relief, while a structural solution requires population growth to be brought under control.

Worldwide, an estimated $3.2 \times 10^{9}$ ha are potentially suitable for food production. However, the major part of this land is already under cultivation and farming pursuits on the remaining land are, on the whole, economically less attractive. Even if, under the present need for food, extensification of the world's agricultural area were pursued with all available means, it is doubtful whether this by itself would improve the long-term prospect. It is therefore imperative to attach high priority to better use of our present land resources. This calls for techniques of land evaluation that enable planners to devise better development strategies which aim at sustainable agricultural production. Quantified Land Evaluation (QLE) procedures have been developed for this purpose by the Centre for World Food Studies. They use concepts as defined in the FAO Framework for Land Evaluation (1976).

Land evaluation concerns not only the technical aspects of agricultural production but also the socio-economic, political, and other conditions under which production takes place in existing or projected land-use systems. The QLE approach presented here is part of a much wider analytical framework that supports the development of national food policies. This wider framework is described elsewhere in this issue (Tims, 1986).

\section{Production situation}

Most 'conventional' land evaluation procedures allow only a qualitative interpretation of the physical production potential of land. 'Class I land' is expected to be more productive under the projected land-use than 'Class II land' but neither productivity estimates nor input requirements are quantified. The reason is obvious: 'land' is a complex entity with properties that change continuously while 'land-use' is practiced. A dynamic and quantitative analysis of complex land-use systems would require a highly sophisticated computer model and a host of accurate data on 


\section{P. M. DRIESSEN}

land, land-use and socio-economic conditions. The construction of such a comprehensive model, fit to describe the performance of any land-use system in any situation, would require years of methodological work and, when completed, it would have limited operational value because of its massive data needs and high running costs.

For practical reasons, it is more attractive to analyse the production possibilities of rigidly defined land-use systems in 'production situations' of limited complexity. Such production situations can be tailored to the specific needs of the planner and allow to examine the influence of one or a few land qualities and/or limitations on the performance of the system. Land qualities that are not examined in a certain production situation are assumed not to constrain crop production. Thus, a production situation refers to a combination of one land unit and one land utilization type. In the present context, the latter is defined as a combination of one specific crop/variety and a set of (fixed) attributes of land-use that indicate the limits to management possibilities. This configuration which considers a 'single land utilization type' (Beek, 1978), forms the basic entity in quantified land evaluation. In the approach followed by the Centre for World Food Studies, production situations of increasing complexity are arranged in a hierarchical order. At the highest hierarchical level, i.e. in 'Production situation 1' (PS-1), possible crop production is solely determined by the amount of solar irradiance that is intercepted by the crop canopy, by the temperature of the production environment, and the physiological properties of the crop (de Wit, 1965). All other land qualities are assumed to fully satisfy corresponding crop requirements. The production level calculated for PS-1 is thus the highest that can be realized on an experimental field; it is the 'potential production'.

At the second hierarchical level (PS-2), the assumption of optimum water supply to the crop is left and the land quality 'actual soil moisture availability' is quantified and compared with the crop's actual water requirement. The result of that comparison is accounted for in the calculations of the potential crop production. In other words, crop performance in PS-2 is determined by the actual intercepted irradiance, the actual temperature and the actual water availability. All other qualities and limitations that influence crop production in normal farming practice (nutrient availability, weed competition, incidence of pests and diseases, etc.) are assumed non-constraining in PS-2. The outcome of a PS-2 analysis is the "water-limited potential production' of the land-use system.

At the third hierarchical level (PS-3), the actual availability of plant nutrients is additionally taken into account. This results in an estimate of the 'water- and nutrient-limited potential production', and so forth.

The lower the hierarchical level of the analysis - i.e. the more land qualities and corresponding crop requirements are considered in a specific case -, the higher is the complexity of the simulated production environment and the closer the resemblance between the production situation analysed and the situation in which farmers normally operate in developing countries. The various production situations in an arrangement as described, are essentially situations in which agricultural research stations conduct their experiments. This facilitates model validation, an essential operation before analyses on a larger scale are attempted. 


\section{The simulation procedure}

The properties of a land-use system change with time: land unit specifications are variable (e.g. the weather) and crop properties/requirements change as the crop grows. It follows that land-use system behaviour can only be simulated in a dynamic fashion. The 'state variable approach' is a suitable technique to do this. It considers a crop growing period as a concatenation of individual (short) time intervals. All dependent VARIABLE values are assumed invariate for the duration of an interval and reflect the STATE of the system during that interval. State variable values are updated after completion of the calculations for each interval; the adjusted values typify the state of the system during the next interval, and so on. The state variable technique has the implicit advantage that interactions between quality-requirement pairs, positioned at different hierarchical levels, are accounted for automatically. Consider, for instance, PS-2: water stress during a certain interval (2nd level) prompts a crop to reduce its water consumption but affects also the physiological activity of plants and thus the rate of leaf growth and the capacity of the canopy to intercept solar irradiance (1st level) during subsequent intervals.

The foregoing may have given the impression that potential production estimates are the outcome of the analysis at all levels. This is not necessarily true. The more land qualities are considered, the more system properties, processes and interactions are involved in the analysis and inevitably a point will be reached where the problem becomes unmanageable. Practice shows that while PS- 1 calculations are still comparatively simple, calculations of potential water-limited productions are often rather complicated. To quantify possible land-use system performance as a function of intercepted irradiance, temperature, water availability and nutrient availability, is extremely difficult. It is therefore considered practical to make a change in strategy; from PS-3 onwards, a target production is postulated (usually the outcome of PS- 2 calculations, sometimes lower but never higher) and the physical inputs, labour, and management requirements for realizing the set production target are quantified. This implies that analyses at level 3 produce, in addition to an estimate of the water-limited potential production, an estimate of the 'nutrient requirement' or 'fertilizer requirement' for realizing the target production (PS-3). The associated labour requirements are estimated by using standard task times for each activity needed. An example: 'broadcast fertilizer application to a grain crop' requires 3 man-hours per hectare if done manually, 2 hours if light equipment is available and 1 hour with engine-powered equipment. Which of these three options applies follows from the set of key attributes that describe the technology and managerial skill with which agriculture is practiced. The hierarchical structure of the analytical framework is illustrated in the diagram of Fig. 1; detailed information on the routines with which the various production situations are analysed, is given by van Keulen \& Wolf (1986).

\section{Regional analysis}

The essence of land evaluation is comparing land characteristics/qualities with land- 


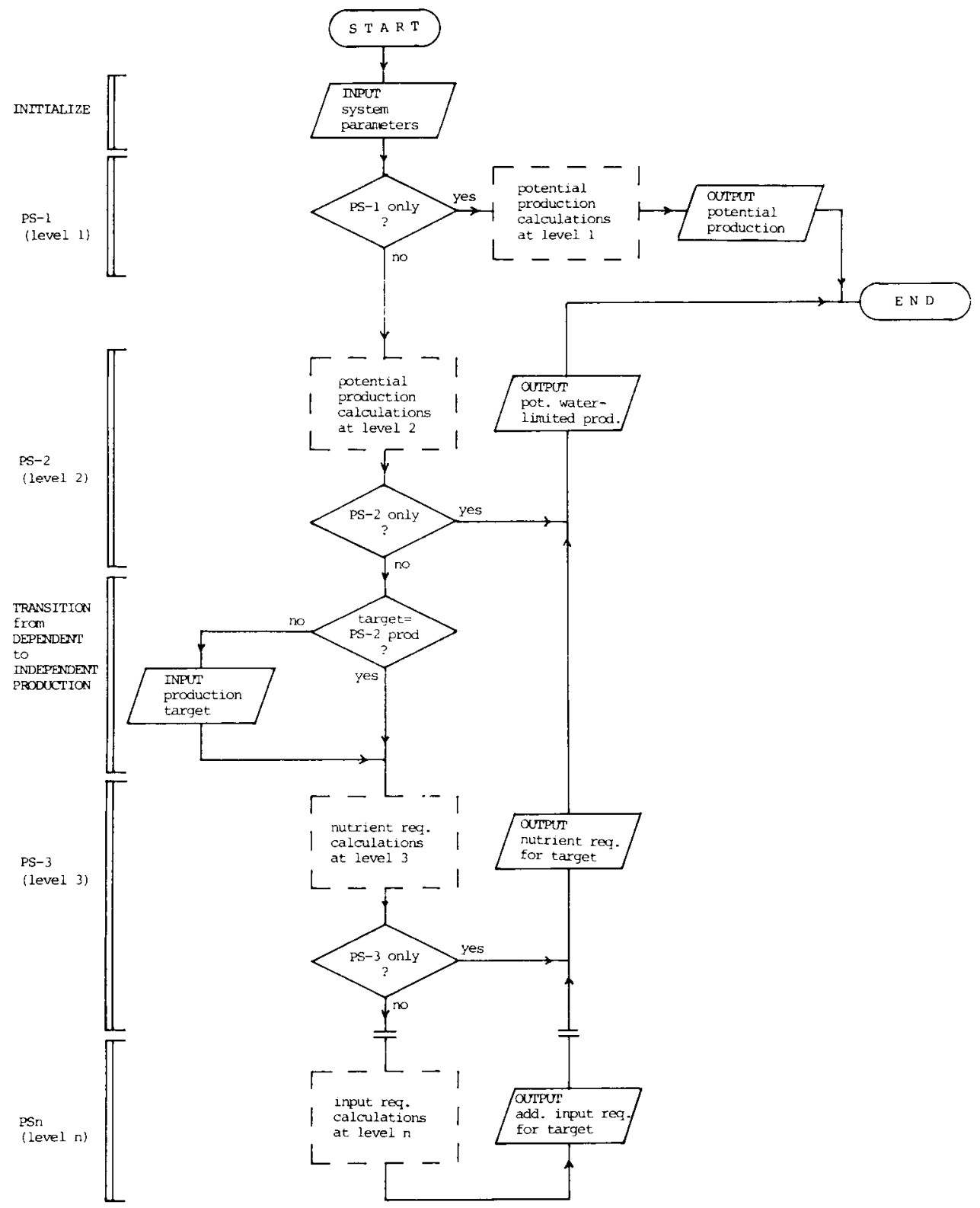

Fig. 1. Framework for the analysis of potential land-use system performance. 
Table 1. Basic information in maps; scale and purpose.

\begin{tabular}{|c|c|c|c|c|}
\hline \multirow[t]{2}{*}{ Type of map } & \multirow[t]{2}{*}{ Scale } & \multicolumn{2}{|c|}{ Grid cell area } & \multirow{2}{*}{$\begin{array}{l}\text { Typical purpose of } \\
\text { evaluation }\end{array}$} \\
\hline & & ha & level & \\
\hline Very detailed & 10000 & 0.2 & plot & $\begin{array}{l}\text { Very detailed } \\
\text { (project) planning }\end{array}$ \\
\hline Detailed & 25000 & 1.2 & small farm & Detailed planning \\
\hline Semi-detailed & 50000 & 5 & farm & Semi-detailed planning \\
\hline Reconnaissance & 200000 & 80 & village & Broad regional planning \\
\hline Broad reconn. & 1000000 & 2000 & district & National land planning \\
\hline
\end{tabular}

use requirements for a situation that is fixed in time and in space. To extend an analysis of individual situations to an analysis of land, a procedure is needed which attributes individual points to spatially delineated tracts of land with a uniform potential for the defined land-use 'The simplest method of storing, manipulating and presenting spatially organized data is to allocate all data to the appropriate cells of a pre-determined grid' (McRae \& Burnham, 1981). For easy identification of site coordinates, the grid is best grafted onto the meridian system. The size of the grid cells must tie in with the purpose of the evaluation and is also a function of the availability and resolution of basic data. Table 1 suggests indicative grid cell dimensions with reference to the purpose of the evaluation and the availability of information from maps. Each grid cell area is described by one set of soil and weather data, so that the smallest land unit that can be analysed has the dimensions and size of one grid cell. A sifting procedure which identifies those grid cells where land suitability for the envisaged type of utilization is clearly nil, is a logical next step. This screening involves comparison of the actual land characteristics of each cell with a set of tabulated minimum land-use requirements. Because the decision to exclude a cell from further analysis is taken on the strength of rather crude indicators, it is prudent to exclude only those grid areas where one or more minimum requirements of landuse are clearly not met. Neighbouring cells with identical data contents can conveniently be combined to larger units in this stage of the analysis. After calculations have been done for all remaining cells and/or aggregations of cells, areas with a uniform potential for the defined type of land utilization can be presented as capability (map) units. If the cells have suitable proportions, maps can be produced with a standard line printer.

\section{Application of quantified land evaluation procedures}

The purpose of a particular land evaluation exercise determines in the first instance at which hierarchical level a land-use system is analysed. Analyses done at level 1 produce estimates of the highest production that is theoretically possible on an open field. Such productions will rarely - if ever - be obtained in practical farming but their quantification is still useful, if only because they represent the technological ceiling in the range of production possibilities that development strategists might consider. 


\section{P. M. DRIESSEN}

Analyses at the second level result in estimates of a level of production that is within reach for many farmers in countries where technical and managerial knowhow are of a high standard and material inputs are available as needed. Production situation 2 is still a long way from the situation in which farmers in developing countries normally operate. Nonetheless, running alternative PS- 2 scenarios permits already to make a comparative analysis of alternative water management strategies, crop selections, planting or seeding dates, etc. It can also help to select promising areas for the introduction of new crops in critical regions, and much more.

PS-3 analyses give an additional possibility to judge the need for fertilizer application.

Apart from their application in (potential) production calculations, QLE procedures are particularly needed in the assessment of land degradation hazards and the associated need for conservation measures. Therefore, the Centre for World Food Studies is increasingly investing research capacity in the development of routines that describe aspects of erosion in a dynamic way and that can be hinged onto (and interact with) the analytical framework as described.

\section{References}

Beek, K. J., 1978. Land evaluation for agricultural development. Publication 23, ILRI, Wageningen.

McRae, S. G. \& C. P. Burnham, 1981. Land evaluation. Monographs on Soil Survey. Oxford Science Publishers, Oxford.

Tims, W. \& D. C. Faber, 1986. Modelling food policies and food production. Netherlands Journal of Agricultural Science 34: 283-294.

Van Keulen, H. \& J. Wolf, 1986. Modelling of agricultural production: weather, soils and crops. Simulation Monographs. Pudoc, Wageningen.

Wit, C. T. de, 1965. Photosynthesis of leaf canopies. Agricultural Research Reports 663. Pudoc, Wageningen. 